\title{
Parallel phases: a study on the high and low left periphery of Old Italian \\ Cecilia Poletto University of Venice
}

\section{Introduction ${ }^{1}$}

In this work I will investigate a set of OV constructions in Old Italian (OI), a phenomenon which has been up to now neglected in the literature on Old Romance languages. Some cases of OV structures can be analyzed as V2 cases, with the Object in (some) SpecC position and the inflected verb in the corresponding $\mathrm{C}^{\circ}$ head. There are however further cases which require a different treatment as the verbal form involved is a past participle, not an inflected verb, as shown in (1):

\section{(1) Allora il cavalero, che'n sìalto mestero avea la mente misa Then the knight that in so high work had.3sg his mind set}

(BL, Tes., v. 1975)

I intend to put forth an analysis in terms of movement of the XP to a low Focus (or Topic) position located to the left of the low $v \mathrm{P}$ phase, similar to (at least one type of) scrambling studied in the Germanic languages (see among others Grewendorf (2005)). That such a low left periphery exists and that it includes Focus and Topic positions has been proposed in recent work by a number of authors (notably Jayaseelan (2001), Belletti and Shlonsky (1995), Belletti (2004) for modern Italian and Paul (2002) for Chinese among others). I will adopt this proposal and show that OI displays an interesting parallel between the high left periphery located in the $\mathrm{CP}$ layer at the external border of the high $\mathrm{CP}$ phase and the low left periphery, so that it is possible to hypothesize that the features of a functional head as Focus are parametrized as phase independent properties. Whenever a Focus head is inserted in the syntactic structure (whether in the high or in the low phase) it is bound to be either strong or weak depending on the language, yielding uniformity of behavior across phases. If this view is correct, it predicts that also in the DP phase similar phenomena should be found, and that whenever the property is weakened and then finally lost, all the phenomena connected to it in each phase are weakened and lost in the same way as well: we will see that V2, scrambling and DP internal movement in the Renaissance period are weakened ${ }^{2}$ in a parallel way. Hence,

1 This work originally stems from my participation to the Italant project for an OI Grammar directed by L. Renzi and G. Salvi. A version of this work has been presented at the Giornata sull'Italiano antico at the University of Padova, at the research seminar of the Georgetown University and at the XXXI IGG conference in Rome. I thank the audiences of these conferences and Paola Benincà, Verner Egerland, Nicola Munaro, Nicoletta Penello, for insightful comments and discussion. The usual disclaimers apply.

${ }^{2}$ What is meant here by weakened is the fact that the Focus position is not obligatorily occupied anymore, but can only be used by a set of elements with operator properties (as for instance adverbials like sempre 'always' and mai 'never'), which is nonetheless larger than the set of operators possible in SpecFocus in MI (a set which includes 
our prediction is borne out. If the general view is correct, it could open up interesting possibilities to translate the old notion of parameter of the GB approach

The article is divided as follows: in section 2 I briefly sketch the peculiar type of V2 displayed by OI, in section 3 I present the phenomenon of scrambling. Section 4 contains an explanation of Egerland's (1996) generalization concerning the relation between $\mathrm{OV}$ and past participle agreement patterns and the core proposal that properties of functional heads must be stated as phase independent properties. Section 5 contains a discussion on quantifiers, which behave differently from definite DPs. Section 6 shows that the high and the low left periphery behave alike with respect to three phenomena already discussed for the CP in section 2. In section 7 I show that the same type of scrambling is found as expected also within the DP phase and in section 8 that Renaissance Italian (RI) has a restricted usage of V2, scrambling in IP and scrambling in DP as expected and that these phenomena are sensitive to the same type of factors, like the presence of a modal verb or the presence of another operator, like a wh-item in relative clauses. Section 9 concludes the article.

\section{The high left periphery of the clause}

As is well known since Benincà (1984), OI shows some (but not all) of the typical correlates traditionally associated with the V2 property, namely subject inversion between the auxiliary and the past participle (not to be confused with free subject inversion, which is still possible in Modern Italian (MI) and occurs after the past participle). ${ }^{3}$ This property has been lost in the Renaissance and is not found in MI.
a.
quali denari avea Baldovino lasciati loro which money had.3sg Baldovino left them

(Doc. fior., 437)

b. ...primieramente avea ella fatta a llui ingiuria ...for first had.3sg she done to him injury

(BL, Rett., 116)

Cases like those in (2) are standardly analyzed as movement of the inflected verb to a $\mathrm{C}^{\circ}$ position, as also assumed for Germanic V2.

The licensing of pro drop is submitted to different requirements in OI with respect to MI and shows that the inflected verb is moving higher in OI than in modern Romance: pro drop in OI is sensitive to the main versus embedded asymmetry: pro drop is found in main clauses but not in embedded ones, where a subject pronoun is always realized (see Vanelli (1987) for a detailed discussion on subject pronouns in embedded contexts in Old Italian).

essentially only wh-items and contrastively focalized XPs)

${ }^{3}$ All examples are taken from the OVI (Opera del Vocabolario Italiano) data base which contains all OI texts from 1200 to 1350 . I follow here Lorenzo Renzi and Giampaolo Salvi (forth.) in defining OI as the Florentine variety written in this period. 
(3) E cosìne provò _ _ de' più cari ch'elli avea.

and so of-it tested.3sg _ of-the most dear that-he had.3sg

(Testi fior.,74)

The standard analysis of this asymmetry is that pro can only be licensed when the verb has moved to the CP layer (cf. Benincà (1984) for OI and Roberts (1993) for Old French).

On the other side, OI does not display any linear V2 restriction typical of V2 languages, as V3 cases are frequently attested ${ }^{4}$.

(4) a. Et dall' altra parte Aiaces era uno cavaliere franco courageous and on the other side A. was a knight

(BL, Rett., p. 94, r. 7)

b. E la reina Artemidora di Alicarnasso, che in adiuto di Serses and the queen A. of Alicarnasso who in help of Serses era venuta, francamente si mescolo nella battaglia was come courageously herself mingled.3sg into the battle

(BG, Or., p. 92, r. 1)

I will adopt here Benincà's (to appear) proposal that in OI the verb moves to the head of an operator projection labeled as FocusP in (5) and located in the lower portion of the CP layer, leaving the higher Topic positions available for other XPs yielding cases of V3. ${ }^{5}$ The structure of the left periphery of OI according to Benincà (to appear) is the following:

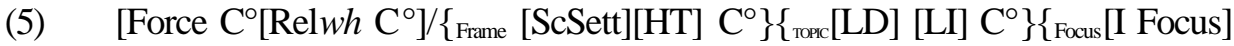
[II Focus]/[Interrwh $\left.] \mathrm{C}^{\circ}\right\}\left[\right.$ Fin $\left.\left.\mathrm{C}^{\circ}\right]\right\}$

The target of verb movement in OI is a projection inside the Focus field, higher positions can only be occupied by Topics (no more than one Focus can be realized due to minimality reasons).

Another interesting peculiarity of $\mathrm{OI}$ is that it makes extensive use of V1 constructions (cf. (6a)), which were much more widespread also in Old Germanic languages with respect to their modern counterpart (see Fuss (2005)). However these cases are analyzed - whether there is a narrative null operator (corresponding to 'then') as proposed for their Germanic counterpart, or whether V1 is due to movement of the verb to the higher Topic field - it is well

\footnotetext{
${ }^{4}$ Cases of V4, V5 and so forth are also attested, this is expected under the hypothesis that there are several topic projections located higher than FocusP (cf. Benincà 1995, 2005). Here I will refer to V3 meaning also $\mathrm{V}^{*}$.

${ }^{5}$ A number of other phenomena are connected to V2, as null topics and past participle fronting. They are left aside here because the purpose of this section is to illustrate the similarities between the CP left periphery and the low left periphery.
} 
know that in these cases clitics are obligatorily found after the inflected verb in enclisis (this is known as a case of the Tobler Mussafia law), as shown in (6b): ${ }^{6}$
a. Avemo ditto che
è rettorica
have. $1 \mathrm{pl}$ told what is rhetorics
b. Leggesi di Salamone che...
Reads-one of Salomone that

(BL, Rett., p. 5, r. 17)

(Novellino, p.138, r. 1)

Therefore, OI displays the following properties connected to the CP left periphery of the clause:

a) V2 constructions in which an XP is preposed to the inflected verb

b) V3 constructions in which a number of Topics could precede the V2 structure

c) V1 with subject inversion

d) Pro drop licensed by $\mathrm{V}$ to $\mathrm{C}$ movement

e) Obligatory enclisis in V1 constructions

We will see that similar properties also hold for the scrambling phenomenon.

\section{XP V as scrambling to Focus}

Once we factor out the cases of XP V ordering triggered by V2, a number of residual cases are still to be explained, the clearest cases being those with the object located between an auxiliary verb (in Focus ${ }^{\circ}$ ) and the past participle. Examples like those in (7) cannot be analyzed as movement of the object to the high Focus position, which is in this case occupied by the subject preceding the auxiliary verb: ${ }^{7}$

(7) a. $i$ nimici avessero già il passo pigliato the enemies had.subj.3pl already the pace taken

b. ch'egli avea il maleficio commesso

(BG, Or., p. 88, r. 15)

that he had.3sg the crime committed

(BG, F. di rett., p. 31, r. 12-13)

c. dice che poi àe molto de ben fatto in guerra et in pace.

says that then has a lot of good done in war and in peace

d. il quale da che ebbe tutto Egitto vinto...

whom since had.3sg all Egypt won...

\footnotetext{
${ }^{6}$ In this work I will use enclisis of the clitic pronoun merely as an empirical test to provide evidence for the similarity between the high and the low left periphery, therefore I will leave aside the complex matter of explaining V1 and deriving enclisis.

${ }^{7}$ Given that OV cases with a simple verb can always be ambiguous between V2 and scrambling I will restrict the data to cases of compound tenses.
} 
(BG, Or., p. 83, r. 15)

On the other side, it is not possible to assume that OI was an OV language as the unmarked word order found in the texts is identical to that of MI and it is typical of modern Romance languages, which are all VO:

(8) a. tenea un savio greco in pregione

kept.3sg a wise Greek in prison

(Novellino, p 125, r. 6)

b. fece menare il destriere al campo let.3sg lead the horse to-the camp

(Novellino, p.126, r. 13)

c. Molto onoroe la donna nel parto

A lot honoured.3sg the woman in-the childbirth

d. Torquato, consolo di Roma, fece per iustizia tagliare

Torquato, consul of Rome, had.3sg for justice cut

la testa al

figliuolo

the head to-the son

(F.V.F., p. 113, r. 2-3)

A revealing feature of the $\mathbf{O V}$ construction is that not only direct objects, but any type of internal argument (including passive subjects) can be found to the left of the past participle:

(9) a. Ed essendo dell' unico guernimento già ispogliato and being of-the only ornament already stripped

b. quello che per uso è già dagli antichi servato

(BG, Or., p. 411, r. 1)

what that usually is already from-the ancients kept

c. Non crederei che fosse per voi rotto.

(BG, Veg., p. 108, r. 25-26)

not would-believe.1sg that was by you broken

d. ch'elli è a fine venuto

(Fiore., p. 442, r. 11)

that he is to end come

e. avegna che neuno possa

(Trist. Ricc., p. 397, r. 17)

perfetto

happens that noone can.subj.3sg good advocate be nor perfect

(BL, Rett., p. 147, r. 1)

f. perciò che quelli cui conviene udire sono già udendo fatigati for that those that have to hear are already listening tired

g. se l'avessi a mente tenuto

(BL, Rett., p. 193, r. 19)

if it-had.subj.1sg in mind kept

(BG, $V e V$, p. 16, r. 5) 
h. Assa' bene, quando sono di te acompagnata very well when am by you accompanied

(BG, $V e V$, p. 33, r. 2)

i. E quand' ebbi cosí chiaramente a ogni cosa risposto and when had.1sg so clearly to everything answered (BG, $\mathrm{VeV}$, p. 37, r. 24)

1 comandò questo giovane che fossero tutte quelle genti menate ordered.3sg this young that were all those people led

(Novellino, p. 143. r. 24)

The same is true for adverbials (either formed by a single word or by a complex constituent) and verbal modifiers in general which in their unmarked order usually occur after the past participle: ${ }^{8}$

(10) a. e holla già molte volte letta nella Bibbia

and have-it already many times read in-the bible

b. a quelli che sono già avanti iti

(BG, $\mathrm{VeV}$, p. 15, r. 22)

to those that are already forward gone

c. da tutta la gente sarai scarso tenuto

(Tes. volg. p. c350, r. 2)

of all the people will-be.2sg poorly considered

(BL, Tes., v. 1561 )

d. Poilo fece fuori trarre

that him made. $3 \mathrm{sg}$ outside take

(Novellino, p. 158, rr. 6-7)

e. il cavaliere era molto bene costumato

the knight was so well educated

(Novellino, p. 311, r. 3)

f. Quand' ebbero così ordinato

when had.3pl so ordered

(Novellino, p. 349, r. 1)

Given that this is not the unmarked word order of OI, I propose that the ordering found in (7), (9) and (10) is due to a movement operation similar to scrambling targeting a Focus position located in the low IP area. Following Belletti (2004) I take this position to be in the left periphery of the low $v \mathrm{P}$ phase. ${ }^{9}$ This is clearly a position dedicated to XPs (no clitic or weak elements can occur there as they cannot be focalized), and it hosts virtually any type of constituent, all types of arguments as well as adverbials and verbal modifiers.

\footnotetext{
${ }^{8}$ The same phenomenon is found with modal verbs and infinitival complements and with causative constructions.

${ }^{9}$ Differently from Belletti (2004) and on a par with Paul (2002), I will not assume that the low left periphery is located lower than "lower adverbials" (in the sense of Cinque (1999)). The position of this set of projections still requires further research, however see section 8 for some discussion on this issue.
} 
This lack of "specialization" in the element that they can host is a feature typical of left peripheral positions, where any type of XP can be moved.

Suppose further that the "left periphery" of each phase is construed in the same way, namely by merging a "Topic-Focus" field before the highest projection "closing up" the phase (corresponding to Force in the CP system proposed by Rizzi (1997); see again Belletti (2004) for MI among others).

Therefore, all examples in (7) (9) and (10) are to be analyzed as cases of movement to a SpecFocus position in front of the past participle but lower than the subject position (SpecAgrS or SpecT in a strict minimalist framework).

\subsection{The relation between scrambling and past participle agreement}

Egerland (1996) examines only cases of direct object scrambling and notices that the OV order is diachronically related to the possibility of past participle agreement with post-participial objects, when post-participial agreement is lost, the OV order is lost as well:

(11) a. quando egli avea già fatti molti miracoli when he had.3sg already done+pl many miracles.pl

b. E quando il notaio ha letta la proposta dinanzi $a^{\prime}$ consiglieri

and when the notare has read.f the proposal.f to the counselors

c. c'ha rifiutata la nobile città di Giadres et ha

that has refused.fem the noble city.fem of Giadres and has

preso li marchi (Novellino, p. 133, r. 3)

taken.m the money.pl

Moreover, he shows that if the order is VO, past participial agreement is optional (as is shown by preso in (11c)) while it is obligatory when the order is $\mathrm{OV}$. This observation is confirmed by modern languages, which still have OV orderings, like Friulian. As is shown below, only three of the four logical possibilities are attested: the sequence OV (12d) without agreement is not possible (see Paoli (1997) for a detailed analysis of this phenomenon in modern Friulian).

(12) a.

Oai lis sigaretis dismenteadis

I have the cigarettes.pl forgotten.pl

b. O ai dismenteadis lis sigaretis

c. Oai dismentea:t lis sigaretis

I have forgotten.sg the cigarettes.pl

d. $\quad * O$ ai lis sigaretis dismentea:t 
We can reformulate Egerland's observations in the form of two descriptive generalizations as in (13) and (14): ${ }^{10}$

(13) When past participial agreement is reduced (and finally lost), OV is reduced (and finally lost) as well

(14) Past participle agreement is obligatory with the OV order, not with the VO order

Both generalizations can be instrumental to shed light on the account of scrambling in OI. Generalization (14) is to be considered a special case of a descriptive generalization proposed by Guasti and Rizzi (2002): basing on cases of subject agreement they note that movement and morphological richness are connected and propose the following generalization:

(15) If a feature is checked in the overt syntax, then it is expressed in the morphology ${ }^{11}$

Generalization (15) captures all cases in which a preverbal subject shows stronger agreement with respect to a postverbal subject: when the subject moves to the specifier of AgrS thus checking the AgrS feature in overt syntax, morphology reflects this process, hence the fullest agreement pattern is always selected. This is not always the case for postverbal subjects, where there is no overt checking of the feature in the syntax. Thus, postverbal subjects differ cross-linguistically as they can either have full agreement, a reduced form of it, or no agreement at all. Given Egerland's generalization, confirmed by Friulian data, this is also true for objects, when the object is checking a given feature in overt syntax, this is obligatorily reflected in the past participle agreement morphology.

Therefore, OV structures are to be intended as cases of overt movement through a position encoding strong features for object agreement ${ }^{12}$ on their way to Focus. The derivation of OV structure is given below (for sentence (7b)):

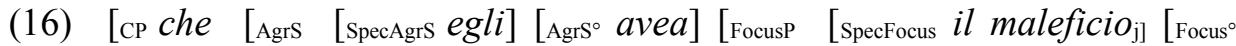
commesso $\left.\mathrm{i}_{\mathrm{i}}\right]\left[\mathrm{AgrOP}\left[\right.\right.$ SpecAgro $\left.\left.\left.\left.\left.\mathrm{t}_{\mathrm{j}}\right]\left[\mathrm{Agro} \mathrm{t}_{\mathrm{i}}\right] \ldots\left[\mathrm{vP}\left[\mathrm{v}^{\circ} \mathrm{t}_{\mathrm{i}}\right]\left[\mathrm{t}_{\mathrm{j}}\right]\right]\right]\right]\right]\right]$

VO structures, on the contrary, are ambiguous between a movement and a non movement analysis. When there is no agreement, the null hypothesis is that no movement has applied to the object DP: given that movement to Focus is not obligatory, the object DP can stay in its base position. On the other hand, when there is object agreement, I assume that the object DP moves to the SpecAgrO

\footnotetext{
${ }^{10}$ For data supporting this generalizations, see Egerland (1996) and section 6.

${ }^{11}$ The generalization has to be interpreted in the following way: whenever a language has strong morphology, this has to be used when the DP precedes the verbal head, it is clearly vacuous with respect to languages that do not have any morphology at all.

${ }^{12}$ This position could be AgrOP, as originally proposed by Kayne (1991) or another functional projection which has other features, as AspP. I will leave this question open here, although I use the label AgrO for the sake of concreteness.
} 
position. This means in turn that the past participle must have moved higher than the SpecAgrO position where the DP has moved, in order to derive the ordering Participle+agr Object. I assume that this position is precisely the head of the Focus projection located in the low left periphery. Hence, the derivation of VO orders is (17a) for non agreeing cases and (17b) for agreeing cases (I take (11b) as a sample sentence):

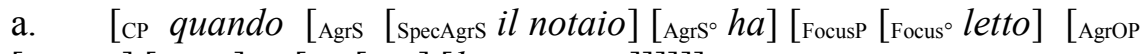

$$
\begin{aligned}
& \text { [SpecAgro }]\left[\text { Agro } \mathrm{t}_{\mathrm{i}}\right] \text {...[vp [vo } \mathrm{t}_{\mathrm{i}} \text { [ [la proposta]]]]]] }
\end{aligned}
$$

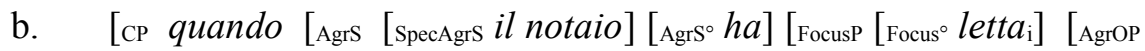

$$
\begin{aligned}
& \text { [specAgro la proposta } \left.\left.\left.\left.\mathrm{j}]\left[\text { Agro } \mathrm{t}_{\mathrm{i}}\right] \ldots\left[\mathrm{vp}\left[\mathrm{v}^{\mathrm{o}} \mathrm{t}_{\mathrm{i}}\right]\left[\mathrm{t}_{\mathrm{j}}\right]\right]\right]\right]\right]\right]
\end{aligned}
$$

In (17a) only the past participle moves by virtue of the head movement constraint (or any minimalist version of it) through the head of AgrO to reach Focus $^{\circ}$, the object does not move. Hence, no agreement is possible. In (17b) on the contrary, not only the participle moves to AgrO, but also the object, triggering agreement. The object is then not further moved to Focus, while the participle does.

Notice that this derives straightforwardly not only generalization (14) but also (13): if a strong agreement is always an instance of movement in OI, then loss of movement directly accounts for loss of strong agreement.

Alternatively, in a minimalist framework where the agreement relation is no more conceived as deriving from the structural relation between a head and its specifier, the agreement pattern with a post-participial object might be derived via an Agree operation applying freely between the features of the object and those of the past participle. ${ }^{13}$

The main difficulty of this approach is that the Agree operation seems as such too unconstrained to account for the fact that Italian has lost at the same time OV and post-participle agreement (namely generalization (13)) and for the fact that the Agree operation is now blocked in MI for post-participial objects, but not for other types of objects like clitics or passive subjects. In other words, the operation Agree as it is usually stated is too liberal to account for the diachronic path we observe here.

One possible way to constrain the operation is to assume that there is only an indirect link between agreement and syntactic movement and hypothesize that Agree only applies to an in situ object when the language also has a corresponding movement operation for the object. However, we have to assume that agreement with a clitic element or with a passive subject in MI is not sufficient to license Agree with post-participial DPs: only scrambling is. Moreover, the pattern of MI, where agreement is maintained only with those elements that have been moved to the left clearly shows that movement and agreement are directly and not only indirectly linked. Therefore I will discard

\footnotetext{
${ }^{13}$ Note that such an hypothesis can also explain Guasti and Rizzi's generalization: given that movement is a complex operation composed of 'match', 'agree' and 'pied-pipe', the fact that agreement is obligatory with movement is straightforward in this account.
} 
this analysis here and will continue to assume that strong agreement and movement are directly related (as shown in (17)).

Notice that if we are on the right track with the idea that scrambling in OI is movement to Focus, there is an interesting parallel between V2 structures and OV structures: in both cases an XP is moved to a SpecFocus and the verb is moved to the head of Focus. If both Focus heads have the same strong property we can hypothesize that the properties of the low Focus position in IP and in the high CP phase remain constant across phases.

It is a fairly standard assumption that the old notion of "parameter" has to be formulated in terms of properties of functional heads. This, however, often leads to postulating a parameter for a single syntactic construction, while the original notion of parameter has proved extremely powerful in the GB framework because it accounts for a number of syntactic constructions under the same abstract property. Assuming that properties of functional heads remain constant across phases is a new way to account for different phenomena (in our case V2 and scrambling) on the basis of the same abstract feature. I will therefore assume the strongest version of this proposal, namely that a parameter corresponds to the "activation" of a given functional head $\mathrm{F}^{\circ}$, whose features must be checked in the computational component wherever it is merged. Hence, Focus in OI maintains the same property throughout all the phases where it occurs: more specifically it must be filled by a verbal head in all phases, the inflected verb fills the Focus ${ }^{\circ}$ of the high CP phase, the past participle fills the Focus $^{\circ}$ of the low $v$ P phase. ${ }^{14}$

In the high CP-phase it triggers the subject inversion phenomenon typical of V2 contexts (and the others phenomena seen in section 2). In the $v \mathrm{P}$ phase it triggers post-participial agreement, $\mathrm{O} \mathrm{V}$ and more generally XP V.

This means that the high and the low left periphery should behave alike in all respects and leads to a number of expectations concerning the low left periphery on the basis of the constructions illustrated in section 2 for the high left periphery. More specifically, I examine here the predictions this hypothesis makes concerning three constructions already discussed above:

a) as there are several left dislocated items in the high left periphery, this analysis predicts that more than one scrambled element above the past participle should be possible as well.

b) as there exists V1 in the high left periphery, this should be the case also in the low left periphery.

c) as V1 constructions always trigger enclisis in the high phase (see section 2 ), it should also be the case in the low phase.

Two additional predictions are made by the analysis proposed here, the first one concerns OI itself: if the strong feature of Focus is phase-independent we should find similar phenomena in the DP as well, given that DP is also a phase (see Giusti (this volume).

The second prediction is a diachronic one, namely that if V2 and XP V are effects of the same abstract property, they should behave alike in the diachronic

\footnotetext{
${ }^{14}$ Note that this is also consistent with the HMC
} 
process of progressive loss. ${ }^{15}$ We will show in section 6,7 and 8 that these predictions are correct.

\section{Quantifier movement}

Not all cases of OV constructions have to be treated as movement to a SpecFocus (or SpecTopic) position. Analyzing the frequencies of the occurrences of OV orderings it appears evident that there is a major difference concerning the type of element moved, as QPs behave differently with respect to DPs. Reading the texts it seems at first sight that the QP tutto 'all, everything' is found much more frequently to the left of the past participle than definite object DPs. This however remains just a frequency effect unless various cases of tutto are distinguished. A further inquiry has been done considering 2000 relevant occurrences of tutto in the whole corpus. ${ }^{16}$ Within the sample I have split the cases of bare tutto with respect to the cases of tutto modified by a relative clause or followed by a DP. The results are that when tutto is modified by a relative clause it never raises before the past participle:

a. e ffue fatto tutto e ccioe che lo ree comandoe and was done all that that the king required.3sg

b. bene servita di tutto cioe ch'ella comanda

(Trist. Ricc. p. 25) well served of everything that that she requires

(Trist. Ricc. p.136)

When tutto is followed by a DP (preposing seems more frequent with a pronoun like questo 'this')

it can be found to the left of the past participle, as shown in (19), but in the majority of the cases, it is found to the right of the past participle, as in (20):

(19) a. e poi ch' elli àe tutto questo trovato per lo suo pensame and then that he has all this found for his own thinking

b. quale da che ebbe tutto Egitto vinto

(BL, Rett. p. 74)

\footnotetext{
${ }^{15}$ An apparent problem is provided by the equation between V2 and scrambling: if the two phenomena are always connected we should expect them to co-occur in all languages. This is clearly not the case, as there are languages with scrambling (for instance Korean) which do not display V2. The problem here is that the definition of V2 and scrambling have to be qualified in terms of properties of a functional projection. The peculiar type of V2 found in OI is not the "standard" one described for Germanic languages, and as such it probably targets a much lower position in the left periphery. In other words, V2 is a complex phenomenon that always involves the left periphery but not always the same FP. The same is true of scrambling, as different types of scrambling (notably A and A') are known in different languages (see Grewendorf and Sternefeld (1990) Grewendorf (2005)). Hence, given that V2 and scrambling do most probably not target the same projection in all languages, this analysis does not predict that the two phenomena always go together.

${ }^{16}$ What is meant here with relevant occurrences are cases with a past participle.
} 
since that had.3sg all Egypt won

(BG, Orosio., p. 83, r. 15)

(20) a. àe insegnato per tutto il libro insine a questo luogo

has taught for all the book until to this place

(BL, Rett.p. 140)

b. à(n)no ve(n)duto tutto $\boldsymbol{i}$ loro podere

have.3pl sold all the their property

c. e hannovi messo tutto loro ingegno $e$ forza

(Doc. fior., p.226)

and have-there put all their intelligence and force

(BG, Orosio p.24)

Finally, when tutto is a bare quantifier, it is always preposed if it corresponds to the direct object (as shown in (21a-c)), whereas it can be (less frequently) found after the past participle when it is introduced by the preposition $d i$ (as in (21d)):

(21) a. chi 'l tene del tutto in sé celato who it-keeps of-the all in himself concealed

(BL, p.178)

b. 'avrei sovente a tutto tuo conforto scritto e risposto answered

would-have1sg frequently to all your comfort written and

c seguire Idio chi à tutto venduto

(BL, Somm., p.197)

follow God who has everything sold

d. e ben fornito di tutto

(Fiore XIII p.232) and well furnished of everything

(Tes. volg., p.98)

Thus, it seems that not only the status of tutto as bare vs. non bare quantifier influences the frequency of preposing, but also the presence of the preposition $d i$. No cases of tutto as direct or indirect object after the past participle have been found.

It is well known that there are positions dedicated to quantifiers to the left of the VP in languages like German and Dutch. We can therefore hypothesize that bare tutto has to raise to a specific position to the left of the past participle which is specified for checking the features of a universal quantifier. Similar proposals for quantifiers have been made by Beghelli (1995)) and Beghelli and Stowell (1997). A possible alternative would be to consider that the position in question is a case position, given that movement is obligatory with direct and indirect object, but optional with a PP introduced by $d i$ 'of'. This however, would imply that all direct and indirect objects have to raise to the case position, which is clearly not true (see above the discussion on scrambling). The only solution I see to account for the fact that movement is 
obligatory only a) when the XP moved is a bare quantifier and b) when it is a direct or indirect object, is to assume that the field in which QPs are hosted is sensitive to case distinctions, so that there are distinct positions dedicated to universal quantifiers according to their case.

The picture on quantifiers is complicated by the fact that, if we examine another bare quantifier, namely niente/nulla 'nothing', we see that it behaves exactly in the opposite way: when the cases of niente as emphatic negation which could be translated with 'at all' (illustrated in (22)) are excluded from the sample, the results are that the quantifier is never moved to the left of the past participle. ${ }^{17}$

a. Non ti annoi niente a visitare $i$ malati not yourself bother.2sg nothing to visit the sick (ZB, p.69)

b. che Dio non ode niente l'orazione that God not hears nothing the preach (ZB, p.

c. falso legno non è niente buono false wood not is nothing good

(ZB, .

a. te n'avea detto niente

to-you of-it had3sg told nothing (Paolino P., p.

b. non avea saputo niente

not had.3sg known nothing (Tav. rit., p. 182)

One might think that the basic difference between tutto and niente lies in the movement of the quantifier: while tutto moves, niente does not. This seems at first sight rather strange, given the hypothesis made here, namely that a QP moves to a specialized checking position. The question is, if there is a specialized position for universal quantifiers, why is there none for negative QPs? Further data showing that niente does not probably remain in the merge position of the direct object are the following:

(24) a. e non vede in lui niente perchè sia degno del pane and not sees in him nothing because be.subj.3sg worth of-the bread

b. dicessono allui niente

(ZB, p. 25)

tell.subj.3pl to him nothing

(ZB, p. 37)

c. sapendo di Paolo niente, venneli uno cotale pensiero knowing of Paolo nothing came.3sg-to-him a such thought

(GC, Vite, p. 88)

${ }^{17}$ The only text where we find preposing of niente is the Decamerone by Boccaccio, which I leave aside, because it is clearly a more artificial language (this text has also been left out in the original selection of texts for the OI Grammar edited by L. Renzi and G. Salvi (to appear) precisely for this problem). 
We have seen above ( see (8)) that the unmarked word order of the internal arguments in OI is the same found in MI, namely accusative-dative. However, when niente is the direct object, it occus after the dative or genitive PP, as shown in (24). Hence, we have to explain two facts: a) the fact that niente occurs after the past participle and $b$ ) the fact that niente occurs after the indirect object PP (which is not the case for non quantified objects). A tentative way to analyze these data would be to consider the two facts as related and assume remnant movement of the VP to the left of the position to which niente has moved in the first step of the derivation.

If this is correct, both tutto and niente move to the left of the thematic position, and probably both target a position specialized for universal and negative quantifiers respectively. The movement of niente however, triggers remnant movement of the VP, while tutto does not. Whether this is due to the negative status of niente is left to future research.

Although the exact derivation of these cases still remains to be investigated, there is a fairly uncontroversial conclusion that we can draw, namely that the movement of bare quantifiers is different from the type of XP movement that we have analyzed in scrambling to the low left periphery in the previous sections. I will therefore leave aside all cases of bare quantifiers in the inquiry on scrambling and discuss the predictions considering the parallelism among phases.

\section{First prediction: the analogy of the high and the low phase}

As seen in section 2, OI displays frequent V3 constructions, where one (or several) Topic precedes the Focus element. This is, as expected, also found in the low left periphery:

(25) a. ed ha'mi la cosa molte volte ridetta and has-to-me the thing many times retold

(BG, Tratt., p.131)

b. Equand'ebbi cosí chiaramente a ogni cosa risposto and when had.3sg so clearly to everything answered

(BG, $V e V$, p. 37, r. 24)

Examples in (25) show that two elements occur to the left of the past participle. In (25a) they are the direct object la cosa and the adverbial XP molte volte, in (25b) the indirect object a ogni cosa and the adverbial XP cosi chiaramente. Notice that this type of adverbial XPs usually occur after the past participle, as shown in (26), hence cases like (25) are genuine cases of multiple scrambling of an argument and an adverbial: ${ }^{18}$

(26) Tullio dice, che 'l fatto è contato chiaramente

T. says that the deed is told clearly

(Tes. volg., p. 138, r. 6-7)

\footnotetext{
${ }^{18}$ Notice that chiaramente in OI can only be a low manner adverb, not a high one as in MI (see Poletto (2004) on this).
} 
The second type of construction frequently found in the high left periphery of the clause is V1. Trivially, cases of V1 are also found in the low left periphery, where all objects and lowest adverbs ${ }^{19}$ are located after the past participle, which is then the first element of the phase. In other words, cases of $\mathrm{V} 1$ in the low phase are "normal" cases of VO:

(27) a. ciò che savi avevano detto intorno alla retorica what that wise had.3pl said about the rhetorics

b. ...fue isbandito della terra ...was banned from-the earth

c. poiche Tullio ae advisati li mali

since T. has seen the evils (BL, Rett., p.12 r.7)

(BL, Rett., p.7 r.19)

(BL, Rett., p.7 r.9)

The third construction found in the high left periphery is the one with V1 and enclisis of a past participle. As for the low phase, it seems difficult to test this possibility as in general it is not possible to leave the clitic inside the low phase, i.e. OI has obligatory clitic climbing to the high phase. ${ }^{20}$ However, absolute participial clauses of non-unaccusative verbs have been analyzed by Belletti (1990) as truncated structures corresponding to AspP in MI. Hence, we can use those cases as a test for our hypothesis:

a. trovò l'arme del re Meliadus, che lli avea fatta sì bella found the weapons of king M.

deliberanza, $e$ donatogli:

that he had.3sg done so nice

disposal and given-to-him and was his mortal enemy

b. Fatto ha chiamare Licomede re, e dettogli che

made has call L. king, and told-him that

faccia chiamare le donne

make call the women

(Arm., Fior., p. 546)

As expected, in these cases enclisis is the rule just like in the high phase. We can conclude that the high and the low left periphery really behave alike with respect to the phenomena observed as predicted by the parallel-phases hypothesis.

\section{Second Prediction: the left periphery of the DP phase}

The second prediction made by the hypothesis that functional properties are phase independent is that within the DP area scrambling phenomena are also

\footnotetext{
${ }^{19}$ By lowest adverbs I intend here those adverbs that are usually found after the past participle both in MI and OI when they are not focalized.

${ }^{20}$ There are Romance languages as Piedmontese that leave the clitic on the past participle, but this is not the case for OI.
} 
possible (and are ungrammatical in MI, as the which has also lost V2 and IP scrambling). One interesting fact about $\mathrm{OI}$ is that it is possible to have modified adjectives in prenominal position (contrary to $\mathrm{MI}$ ):
a. domandò se avesse asked if had.subj.3sg
più care pietre
more valuable stones
b. qual ti sembra di più ricca valuta?
(Novellino, p. 123, 54) which to-you seem of more rich value?
c. Democrito fue molto grande filosofo. Democrito was very great philosopher
(Novellino, p. 127, 28)

$$
\text { (F.V.F., p. 106, r. 2) }
$$

How to interpret examples like (29) becomes clear when we notice that adjectives only occurring in postnominal position in MI can occur to the left of the noun:

(30) a. la quale guardava al figliuolo piccolo del morto fratello, whom looked.3sg at-the child young of-the dead brother $\begin{array}{ll}\text { b. } & \text { e dagli usati uomini } \\ \text { and from-the experienced men } & \end{array}$ (BG, Or., p. 148, r. 7)

c. il ben usato cavaliere disidera battaglia

(BG, Veg., p. 167, r. 167) the well behaved knight wants battle

(BG, Veg., p. 70, r. 6)

We can hypothesize that adjectives that are located in a postnominal position in MI can move to the left of the noun due to a DP internal scrambling process, and that modified adjectives do the same in OI. Empirical evidence that the basic position of the adjective is much lower in the structure than the one where the adjective appears and that, in other words, we do not have to do here with a language in which the noun raises very little and most adjectives are found to its left (like Germanic languages for instance) is provided by examples like the following:
(31) a $e$ di gentile aspetto molto and of kind appearance very
(Dante, Vita Nuova, cap. 8, par. 1, v. 11)
b e ciò non è propia natura di cavallo and this not is own nature of horse

(Novellino, p. 128, r. 67)

In (31a) the adjectival modifier molto 'very'has remained to the right of the head noun aspetto 'appearance' and only the bare adjective gentile 'kind' has been extracted out of the complex adjectival phrase and scrambled to the left of the noun. In (31b) the portion of the AdjP left to the right of the noun is its 
complement PP di cavallo. Cases like (31) clearly show that the prenominal position is not a base generated one, but it is due to movement of the entire modified AdjP or of part of it. An even more interesting case is provided by examples like (32):

$$
\begin{aligned}
& \text { quando vi dissi del cavallo cosa cosi meravigliosa } \\
& \text { when you told.1sg of-the horse thing so wonderful }
\end{aligned}
$$

b. Sì come quando ordino di ritrarre dell'antiche scritte

(Novellino, p. 120 r. 14) so as when order.1sg to draw of-the ancient writings le cose che... the things that

These examples show that it is possible to move even the complement PP of a noun (in (32a) del cavallo, in (32b) dell'antiche scritte) to its left. Given that in general object PPs are generated to the right of the noun (OI is not a head-final language), (32) clearly shows that OI had a scrambling process in the DP as well as in IP, thus confirming our prediction. ${ }^{21}$ The scrambling process can be interpreted as movement to either a Focus or a Topic position in the left periphery of the DP area similar to the one of the other phases.$^{22}$

\section{Third prediction: the loss of the medieval system}

As discussed above, the hypothesis that IP-scrambling, V2, and also DPscrambling depends in OI from the same abstract property concerning the

\footnotetext{
${ }^{21}$ A speculation left for future work is the possibility to connect DP scrambling to the fact that OI had very frequent determinerless DPs, in contexts which are completely excluded in MI as in (i). If the parallel between the three phases is complete, the head noun also has to raise to the head of the DP internal Focus position and through this possibly to the higher $\mathrm{D}^{\circ}$ position. Evidence for $\mathrm{N}^{\circ}$ to $\mathrm{D}^{\circ}$ movement (through Focus ${ }^{\circ}$ ) in OI is provided by the frequent cases of determinerless nouns with postnominal possessive adjectives, as illustrated in (ii)

(i) a. esser figliolo di pastore (Novellino, $\mathrm{p} 128$ )

to be son of shepherd

b. che uomo vecchio dicesse cosi grande villania (Novellino, p. 129)

that man old said.subj.3sg so big rudeness

c. con moltitudine di gente in assedio (Novellino, p. 130)

with lot of people in siege

d. donami cavallo e somiere e dispendio ...( Novellino, p. 131) give-me horse and helmet and money

e. mandò per maestri (Novellino, p. 127)

$$
\text { sent.3sg for masters }
$$

(ii) a nostra magione (Novellino, $\mathrm{p}$ 128)

to our home

${ }^{22}$ Contrary to Giusti (this volume)and following Giusti (1996) the hypothesis that phases are construed in a parallel way leads to the assumption that Focus is present also $n$ the DP phase.
} 
strong properties of a Focus head located in the left periphery of each phase predicts that all these properties are lost together at the same time and at the same rate. In order to test the prediction, a XVI century text has been examined and screened for all the cases of subject inversion, IP scrambling, agreement with a post-participial object, and DP scrambling. The text chosen is "Il Principe" by Machiavelli, of which the first X chapters and chapters XX-XIII have been analyzed.

The first phenomenon considered is V2: all cases of subject inversion and cases in which new information focus (ungrammatical in MI) is found in first position have been marked. In the whole sample there are only three cases of subject inversion with an auxiliary verb (cf. (33)) and eight cases with modals (six with potere 'can' and two with dovere 'must'). Cases with modal verbs are illustrated in (34): ${ }^{23}$

(33) a. Spenti adunque questi capi, e ridotti $i$ partigiani

loro

blown off then these bosses and reduced the partisan their amici suoi, aveva il duca gittato assai buoni

fondamenti

friends his had the duke thrown very good foundations

alla potenza sua

to-the power his

b. Aveva adunque Luigi fatto questi cinque errori

(p.197)

had then L. made these five mistakes

c. Mentre che durò la memoria, sempre furono $\boldsymbol{i}$ Romani while that lasted.3sg the memory always were the Romans incerti di quella possessione

unsure of that possession

(34) a. E deve soprattutto uno principe vivere con $i$ suoi sudditi and must.3sg overall a prince live with the his subjects in modo che ... $\begin{array}{llll}\text { so that... } & & & \\ \text { E con più facilità se } & \text { (p.237) }\end{array}$

principe and with more easyness for-himself them can.3sg a prince guadagnare gain

As for cases in which Focus appears in first position, a feature typical of OI syntax, there exist only four cases of this type (shown in (35)) if we factor out the two adverbs sempre 'always' and mai '(n)ever', which are very frequently placed in first position even in contexts where they do not

\footnotetext{
${ }^{23}$ The difference between modal verbs and auxiliaries might simply be due to the fact that compound tenses are less frequent in OI than in MI. I will leave the investigation of this difference to future research.
} 
seem to be contrastively focalized (in which case they are still possible in MI as well):

a. Confido assai che per sua umanità gli debba essere accetta trust.1sg a lot that for his umanity to-him must be accepted

(p. 173)

b. Più facilmente si tiene una città usa a vivere libera more easily one keeps a city adapted to live free con il mezzo dei suoi cittadini, che in altro modo with the means of-the its citiziens that in other way (p.204)

c. Come di sopra si disse as above one said.3sg
a. Sempre si trova dei malcontenti always one finds some grudging
b. Mai si troverà ingannato da lui never himself will-find.3sg cheated by him

Notice that in non V2 languages like Spanish and Catalan adverbs like corresponding to OI sempre and mai are always found to the left of the inflected verb and are probably located in a dedicated position inside the Focus layer (see Grava (2005)), so they cannot be taken as real indications of a V2 grammar. It has already been noted for Old French (see among others Roberts (1993)) that some elements "resist" more than others the loss of the V2 system, and are found in V2 constructions also in texts which do not present obligatory V2 anymore. Apparently this is also the case in OI. ${ }^{24}$

Relative clauses deserve particular attention, as V2 cases embedded under the relative complementizer or a wh-item are the overwhelming majority with respect to relative clauses that do not present a V2 effect.
a. Quelli i quali per vie virtuose simili a costoro diventano those who along ways winding similar to them become.3pl principi princes
b. Quelli che di sua qualità gli avevano invidia the ones that of his qualities to-him had.3pl envy
c. Quelle armi che vicine lo potevano offendere those weapons that close him could.3pl offend

Apparently, the context of relative clauses is special in maintaining V2 longer with respect to other clause types, and this is probably due to the fact that in these cases the CP layer is already activated by the wh item sitting in a higher relative position (see Rizzi (1997) on the position of relative elements) which neverless leave the Focus position free for V $2 .^{25}$

\footnotetext{
${ }^{24}$ I leave a list of the elements that undergo V2 longer than others to future research, as the main topic of the present discussion is the establish a parallel among phases.

${ }^{25}$ One might wonder why this is not the case in interrogative clauses, where a wh-item activates the CP layer. However, as already shown by Rizzi (1997) interrogative whitems are located low in the CP structure, in the same Focus field where V2 occurs in
} 
Egerland (1996) proposed that at this stage two grammars were available, one simulating the OI syntax, which is less frequently used and the new one, in which V2 has already been lost. If we are on the right track, it seems that the V2 option still available is subject to specific conditions and very limited in its use. As for IP scrambling, we have a parallel situation: very few cases of scrambling are found in the sample and are all restricted to compound tenses with the auxiliary essere 'be' or copular clauses.

(38) a. Non è, oltre a questo, la provincia spogliata da' tuoi ufficiali not is, beyond this, the province stripped by your officers

b. E benché dai Cartaginesi fusse due volte rotto and although by $\mathrm{C}$. was twice broken

c. Da coloro che saranno in quella malcontenti by those who will-be.3pl in that unhappy

d. Non consentono che sia tra gli eccellentissimi not consent.3pl that be.subj.3sg among the best uomini celebrato men celebrated

e. che senza l'una e l'altra fu da lui conseguito that without the one and the other was by him achieved

Two cases with have have been found, both in a construction with a bare noun:
a. Che esso abbia
con loro obbligo
that it have.subj.3sg with them obligation
b. Altrimenti non ha nelle avversità rimedio otherwise not has in-the misfortune remedy

Most of the exampes are with modals (recall that the same observation has been made for subject inversion in the case of V2) or in causative constructions:

(40) a. Lo può con grandissima difficoltà perdere

it can.3sg with greatest difficulty loose

b. Si possono con più difficultà corrompere one can.3pl with much difficulty bribe

c. Tanto potette in su tale fondamento edificare ogni edificio somuch could.3sg on this foundation build every building

d. Fece da' suoi soldati uccidere tutti $i$ senatori e $i$ più ricchi made by his soldiers kill all the senators and the richest del popolo

(p.232) of-the folk

e. Non abbiano ancora mai potuto ne' tempi pacifici mantener lo not have.1pl yet ever could in times peaceful keep the

OI. Therefore, interrogative wh-items and V2 are not compatible. 
Stato

state

(p.235)

f. Che non $f a$ i fondamenti prima, li potrebbe con una that not does the foundations before them could.3sg with a gran virtù fare dipoi great virtue do afterwards

g. Per potere con quelli tenere il papa in freno for can with those keep the pope at bay

Post-participial agreement is also extremely rare, only five cases are found in the sample:

(41) a. Per aver tenuta più lunga possessione in Italia for have kept.f more long possession.f in Italy

b. Basta avere spenta la linea del principe che enough have turned.f off the line of-the prince who li dominava them dominated

c. Se egli avesse osservate le regole sopradette

$e$

if he had.subj.3sg observed.f.pl the rules.f.pl aforementioned and tenuti sicurie difesi tutti quelli suoi amici

kept.m.pl safe and protected all those his friends.m.pl(p.195)

d. Avrebbero sempre tenuti gli altri discosto dalla

had always kept.m.pl the others away from-the

impresa di Lombardia

(p.197)

enterprise of Lombardy

e. Si vedrà lui aversi fatti granfondamenti

one will-see.3sg him have-himself done.m.pl great foundations alla futura potenza

to-the future might

Interestingly, past participle agreement is extremely frequent in relative clauses, which are exactly the same construction in which V2 is still quite consistently found, as discussed above:

(42) a. La quale opera io non ho ornata né ripiena di the which deed I not have adorned.f nor filled.f of clausole ample

clauses big

b. E quelli fondamenti che gli altri hanno fatti avanti che and those foundations that the others have done.m.pl before that diventino principi (NM, Princ., p.213) become princes

c. Di quelli cardinali che lui avesse offesi of those cardinals that he had.subj.3sg offended.m.pl 
We can conclude that scrambling and post-participial agreement are also extremely restricted and are more frequently found in the same contexts still triggering V2, namely with modals and relative clauses. DP scrambling, as expected, is also quite restricted but still present:

$$
\begin{aligned}
& \text { a. Ed uno de maggiori rimedii e più vivi } \\
& \text { and one of main remedies and more powerful } \\
& \text { b. Troverà difficultà grande } \\
& \text { will-find.3sg difficulty great }
\end{aligned}
$$

Therefore, I conclude that the Renaissance system treats consistently all the phenomena I claim to depend from the same abstract property of a Focus head. The phenomena are all still present, though apparently only in some constructions, which, at least for V2, scrambling and past participle agreement seem to be the same. Further investigation is needed to exactly determine which elements maintain for a longer period the ability of moving to the Focus head (be it in the DP, $v \mathrm{P}$ or CP phase), but what can already be seen is that the three phenomena of V2, IP-scrambling and DP scrambling are weakened in a parallel way.

\section{A comparative note}

If the idea that phases are built in a uniform way and that the formal properties of the functional projections are constant across phases is correct, we predict that the phenomena discussed in this work always go together, a prediction which is plainly wrong. As already note above, there are indeed languages in which V2 and scrambling go together, as German and Dutch, but there are languages like Korean that exhibit scrambling but not V2. However, given a highly split left periphery of each phase, we have to establish which projection V2 (and scrambling) targets, as these are phenomena that can involve different projections, although all located in the peripheral area of a phase.

The idea that V2 is a complex phenomenon and can be analyzed as involving different projections is generally accepted in the literature: it is well known that even inside the domain of Germanic languages the projection targeted by V2 can be different (see on this the so called "symmetrical V2 languages" like Icelandic and Yiddish, or the distinction between Mainland Scandinavian languages and German in embedded V2 contexts under bridge verbs, where the complementizers can be expressed or not (see Vikner (1995)). Moreover, Zwart (1993) has shown that subject initial sentences are different from sentences beginning with a focalized XP. Whatever the analysis of these differences turns out to be, it is clear that V2 is not a uniform phenomenon in the sense that it always targets a single projection. ${ }^{26}$

The same is true for scrambling, in the literature we find distinctions on long and short scrambling (languages like German only exhibit short

\footnotetext{
${ }^{26}$ For an analysis that treats Romance and Germanic V2 as stemming from different CP projections see Poletto (2002).
} 
scrambling, while Japanese for instance also exhibits long scrambling outside the simple clause (see Grewendorf and Sternefeld (1990)); moreover, sometimes scrambling seems to have the typical properties of A-movement, in other cases it behaves as A'-movement (and there are cases that display mixed properties as well). Going through the literature on scrambling, the reader gets the impression that different phenomena have been gathered under the same label and that scrambling does not always target the same functional projection. Therefore, before considering the cases mentioned above as real counterexamples to the idea that the same phenomenon can occur across phases (and be termed differently), we need a very detailed analysis of scrambling and V2 phenomena in all languages that allow for them.

Another possible problem for the parallel phases idea turns out in connection with MI: how come MI does not allow either scrambling or V2 but the Focus and Topic projections can host XPs both in the high and the low left periphery (see on this Rizzi (1997), Benincà and Poletto (2004) and Belletti (2004))? The distinction between OI and MI does not concern the specifier position, which can clearly be filled in both languages, but the head of the Focus (and Topic) projections involved. Following Benincà (2005) I assume that in OI the head of these projections (both in the high and the low phases, and, as we have seen also in the DP phase) is filled by the lexical head (V or $\mathrm{N}$ ), when an element is realized in its specifier, while this is not the case in MI, where no element is required in Focus ${ }^{\circ}$ or Topic ${ }^{\circ}$ and only the specifier of these projections is realized (apart from wh-main contexts, where, following Rizzi (1991) I assume that there is indeed verb movement). The difference between the two languages is precisely a difference in the classical terms of V2, namely whether the head contains strong features or not.

\section{Conclusion}

In this work I have tried to show that OI is not only a V2 language, but also has scrambling to a Focus position internal to the IP layer. Scrambling is both diachronically and synchronically connected to past participle agreement: when scrambling occurs agreement is obligatory, while it is optional when the object occurs in a post-participial position; moreover the two phenomena disappear at the same time. I have adopted an analysis of past participial agreement in terms of syntactic movement (and rejected an analysis in terms of Agree with in situ objects) of the DP to a SpecAgrO position and further movement of the past participle to Focus.

If $\mathrm{OV}$ orders are analyzed as such, new perspectives open up for a unitary treatment of functional projections that occur in different phases: if Focus is marked strong in OI independently of the phase where it is merged, V2 and scrambling are the two sides of the same coin, only one occurring in the high, the other in the low phase. We have seen that the two phenomena have a number of properties in common, as the possibility of V1 and V3 on a par with V2. The hypothesis of a feature uniformity in all phases further predicts that the same type of reordering phenomena is also found within the DP, which is confirmed by the cases of prenominal adjectives and PPs present in the sample. 
The last prediction is that all reordering phenomena: V2, IP scrambling, past participle agreement, and DP scrambling are lost at the same time. A close examination of a Renaissance text shows that they all occur mainly in restricted contexts, as relative clauses and modal and very sporadically in other contexts.

Such a far reaching hypothesis as the one assuming the uniformity of features across phases must clearly be tested in other functional domains, and in other languages. The first domain of inquiry are other Old Romance languages, to see whether the connection between V2 on one side and IP and DP scrambling on the other is confirmed. ${ }^{27}$

\section{References}

Beghelli, Filippo (1995). The Phrase Structure of Quantifier Scope. Ph.D. Thesis, UCLA.

Beghelli, Filippo and Tim Stowell, (1997). Distributivity and Negation: the Syntax of each and every, in A. Szabolcsi, (ed.), Ways of Scope Taking. Kluwer, Dordrecht.

Belletti, Adriana (1990). Generalized Verb Movement. Rosenberg and Sellier, Turin.

Belletti, Adriana (2004) Aspects of the Low IP Area. in The structure of CP and IP Luigi Rizzi (ed.) Oxford University Press, New York, 16-51.

Belletti, Adriana and Ur Shlonksy (1995). The Order of Verbal Complements: a Comparative Study. Natural Language and Linguistic Theory. 13, 489526.

Benincà, Paola (1984). Un'ipotesi sulla sintassi delle lingue romanze medievali. Quaderni Patavini di Linguistica, 4:3-19.

Benincà, Paola (1995). Complement Clitics in Medieval Romance: the ToblerMussafia Law. In Adrian Battye and Ian Roberts (eds.), Clause Structure and Language Change, Oxford University Press, New York, 325-344.

Benincà, Paola (2005). A Detailed Map of the Left Periphery of Medieval Romance, to appear in Zanuttini, Raffaella, Héctor Campos, Elena Herburger and Paul Portner (eds.) Negation, Tense and Clausal Architecture: Cross-linguistics Investigations. Georgetown University Press.

Benincà, Paola and Cecilia Poletto 2004. Topic, Focus and V2: defining the CP sublayers, in The structure of $C P$ and IP, Luigi Rizzi (ed.) Oxford University Press, New York, Oxford, 52-75.

Cinque, Guglielmo (1999). Adverbs and Functional Heads. Oxford University Press, Oxford.

Egerland, Verner (1996) The Syntax of Past Participles. Lund University Press, Lund.

Fuss, Eric (2005) Kongruenzphenomene. Ph.D. dissertation, University of Frankfurt.

${ }^{27}$ In Ledgeway (to appear), he notes that Old Neapolitan has the same features that OI displays, and Old French seems to confirm the connection as well. 
Giusti, Giuliana (1996) Is there a FocusP and a TopicP in the Noun Phrase Structure? In University of Venice Working Papers in Linguistics 6.2, 105128.

Giusti, Giuliana (this volume) On some parallels on clausal and nominal periphery.

Grava, Roberta (2005) Estudio Comparativo entre Italiano Espanol y Catalan sobre la posicion de los denominados adverbios "bajos". Graduation thesis, University of Venice.

Grewendorf, Günther (2005). The Discourse Configurationality of Scrambling. In Joachim Sabel and Mamoru Saito (eds.), The Free Word Order Phenomenon: Its Syntactic Sources and Diversity, Mouton de Gruyter. Studies in Generative Grammar 69, 75-135.

Grewendorf, Günther and Wolfgang Sternefeld (1990). Scrambling and Barriers. John Benjamins, Amsterdam.

Guasti, Maria Teresa and Luigi Rizzi (2002) Agreement and Tense as distinct Syntactic Positions: Evidence from Acquisition. In Guglielmo Cinque (ed.) Functional Structure in DP and IP. Oxford University Press: New York, 167-194.

Jayaseelan, Karattuparambil A. (2001). IP-internal Topic and Focus Phrases. In Studia Linguistica 55.1, 39-75.

Kayne, Richard (1991). Romance Clitics, Verb Movement and PRO. Linguistic Inquiry, 22. 1991. 647-686.

Ledgeway, Adam (to appear) Old Neapolitan Word Order: Some Initial Observations. in: Anna Laura Lepschy and Arturo Tosi (eds), Histories of the Italian languages, Oxford, Legenda.

Paoli, Sandra (1997) Agreement: a Relational Property or a Functional Projection? Evidence from Part Participle Agreement in Friulian. Master thesis. University of York.

Paul, W. (2002).Sentence Internal Topics in Mandarine Chinese: the

Case of Object Preposing. Language and Linguistics. 3,4:695-714.

Poletto, Cecilia (2002). On V2 and V3 sequences in Rhaetoromance, in Sjef

Barbiers, Leonie Cornips and Susanne van der Klei (eds.) Syntactic

Microvariation, http://www.meertens.nl/books/synmic/pdf/poletto.pdf

Poletto, Cecilia (2004). La struttura della frase in Italiano antico. Ms University of Padua.

Renzi,Lorenzo and Giampaolo Salvi (forthcoming). Grammatica dell'Italiano Antico. Bologna, Il Mulino.

Rizzi, Luigi (1997). The Fine Structure of the Left Periphery. In Liliane Haegeman, ed., Elements of Grammar, pages 281-337. Kluwer, Dordrecht.

Roberts, Ian (1993). Verbs and Diachronic Syntax: a Comparative History of English and French. Kluwer, Dordrecht.

Vanelli, Laura (1987). I pronomi soggetto nei dialetti italiani settentrionali dal Medio Evo ad oggi. Medioevo Romanzo, XIII:173-

211.

Vikner,Sten. (1995). Verb Movement and Expletive Subjects in the Germanic Languages. Oxford University Press, New York. 
Zwart, Jan-Wouter (1993). Dutch Syntax. A Minimalist Approach. Ph.D. dissertation, University of Groningen.

\author{
Abbreviations for sources used in the text \\ Arm. $=$ Armannino: Fior.$=$ Fiorita \\ $\mathrm{BG}=$ Bono Giamboni: $F$. di rett.$=$ Fiore di rettorica, Or.$=$ Orosio, Tratt.$=$ \\ Trattato di Virtù e di Vizi, Veg. = Vegezio, VeV = Vizi e Virtudi \\ $\mathrm{BL}=$ Brunetto Latini: Rett.$=$ Rettorica, Somm.$=$ Sommetta ad amaestramento \\ di componere volgarmente lettere, Tes. $=$ Tesoretto \\ $\mathrm{GC}=$ Guido Cavalcanti: Vite \\ Doc. fior. $=$ Documenti fiorentini \\ Fiore:Il Fiore e il Detto d'Amore attribuibili a Dante Alighieri,. \\ F.V.F. = Fiori e vita di filosafi \\ Paolino $=$ Paolino Pieri, Merlino \\ Tav. rit. = Tavola ritonda o l'Istoria di Tristano \\ Tes. volg. = Tesoro di Brunetto Latini volgarizzato da Bono Giamboni \\ Testi fior. $=$ Testi fiorentini \\ Trist. Ricc. $=$ Tristano Riccardiano \\ $\mathrm{ZB}=$ Zucchero Bencivenni
}


Answers to comments

it seems to me that the $\mathrm{OV}$ order is connected with embedded (subordinate/relative) clauses (cf. (7)) - while in (8) the VO order is given in matrix clauses. Am I correct? This might be relevant from a comparative point of view (cf. the same asymmetry in German)

$\mathrm{NO}$, OV order can be found in both main and embedded domains, there seems to be no distinction according to the main/embedded character of the clause.

In )9c) the translation has to be by not for.

does this generalization (only) concern subject DPs?

NO, Rizzi and Guasti generalization concerns all cases of Agreement, although they mainly exemplify it with subjects.

The idea is really that the Focus feature is phase independent, and not dependent, so there is no typo at the end of page 10.

well, in fact with scrambling of più is fine in MI, cf.: "il mio più caro amico", "è il più grande bugiardo che io conosca"

only as superlatives, the cases quoted here from OI are impossibile.

I do not see why the claim that different construction are lost at the same time is too strong, the text by Machiavelli clearly shows that this is the case. 